\author{
How to cite this article: \\ Authors: Anna Bazan, Andrzej Kawalec, Ireneusz Chmielik \\ Title of article: "Application of map and motif analysis for the wear evaluation of abrasive grains on single-layer \\ grinding wheel" \\ Mechanik, No. 12 (2018) \\ DOI: https://doi.org/10.17814/mechanik.2018.12.199
}

\title{
Application of map and motif analysis for the wear evaluation of abrasive grains on single-layer grinding wheel
}

\author{
ANNA BAZAN \\ ANDRZEJ KAWALEC \\ IRENEUSZ CHMIELIK *
}

Dr inż. Anna Bazan, abazan@prz.edu.pl, https://orcid.org/0000-0002-0642-3958 - Politechnika Rzeszowska, Rzeszów, Polska

Dr hab. inż. Andrzej Kawalec, ak@prz.edu.pl, https://orcid.org/ 0000-0002-2120-8535 - Politechnika Rzeszowska, Rzeszów, Polska

Dr inż. Ireneusz Chmielik, p.chmielik@taylor-hobson.pl, https://orcid.org/0000-0002-1407-9069 - Taylor Hobson, Warszawa, Polska

The article presents the possibilities of using the MountainsMap Premium 7.4 program in the context of quantitative analysis of $\mathrm{cBN}$ abrasive on the single-layer grinding wheel active surface at various stages of grinding wheel wear. Two methods of grain separation available in the above software, i.e. island analysis and motif analysis, were compared.

KEYWORDS: grinding wheel topography, grinding wheel wear, single-layer grinding wheel

\section{Introduction}

In multi-task and multi-axis grinding centers - especially in the production of components for the aviation and automotive industries - super-hard grinding wheels (cubic boron nitride cBN or polycrystalline diamond PCD) with galvanic binder [1-3] are increasingly used, allowing for the use of higher grinding speeds, and consequently reducing the cutting forces, extending the life of the grinding wheel and improving the quality of the ground surface [4-6]. Such grinding wheels are usually produced as single-layer ones. Abrasive grains forming a single layer of abrasive are bonded to the metal core of the grinding wheel with a binder, mainly nickel (fig. 1).

The entire cutting potential of such grinding wheels is contained in a single layer of abrasive and it is impossible to restore their cutting properties in the dressing process. Due to relatively high cost of grinding wheels made of super-hard materials (including single-layer ones) and the need to effectively use these tools, research on the wear of the abrasive layer is important. The problem is the description of the topography of the grinding wheel active surface (GWAS), which would allow for quantitative assessment of changes in GWAS topography due to the wear [7-9].

The purpose of the work was to determine the possibility of quantitative assessment of GWAS wear based on measurements and analysis of GWAS topography at various stages of grinding wheel operation. This analysis focused on the study of islands, representing grains, above a specific cut-off level, and pits below the assumed cut-off level.

Islands on the measured object corresponded to the abrasive grains or their highest fragments, and the depressions represented pits in the binder, resulting from its natural unevenness or resulting from the removal of abrasive grains. In the study of grinding wheel wear, deep recesses after removing the abrasive grains were important.

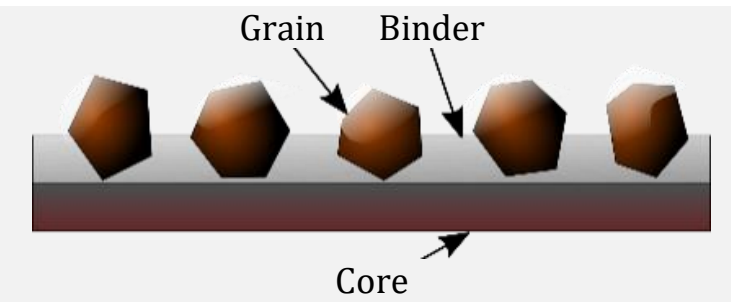

Fig. 1. Schematic structure of a single-layer grinding wheel 


\section{Research methodology}

A single-layer grinding wheel with galvanic nickel binder and cBN abrasive with grain number B35 (average grain diameter $d_{\mathrm{g}}=35 \mu \mathrm{m}$ ) was assumed in the tests. The thickness of the binder layer was $50 \div 60 \%$ of the average grain diameter. The grinding wheel was conical with a maximum diameter of $d=100 \mathrm{~mm}$ and a cone angle of $140^{\circ}$. The workpieces were made of Pyrowear 53 high-alloy steel with a surface hardness of 81 HRA. Surface grinding processes were carried out on a Michael Deckel Fortis grinder. The following adjustable parameters were used: grinding speed $v_{\mathrm{s}}=30 \mathrm{~m} / \mathrm{s}$ (for grinding wheel diameter $d=100 \mathrm{~mm}$ ), tangential feed rate $v_{\mathrm{ft}}=4250 \mathrm{~mm} / \mathrm{min}$, grinding depth $a_{\mathrm{e}}=20 \mu \mathrm{m}$.

It was assumed that measurements of GWAS topography would be carried out at various stages of grinding wheel wear, so that the abrasive loss resulting from GWAS wear can be quantified. Interrupting the grinding process, removing the grinding wheel from the tool holder (to measure GWAS microgeometry) and reinstalling the grinding wheel would be very time-consuming. For this reason, the GWAS topography was decided to be mapped using replicas. The replicas were made using the Struers RepliSet system, with black silicone rubber with details reproduction capacity above $0.1 \mu \mathrm{m}$. For measuring the topography of GWAS replicas, an InfiniteFocus microscope from Alicona (fig. 2) with $\times 20$ lens was used.

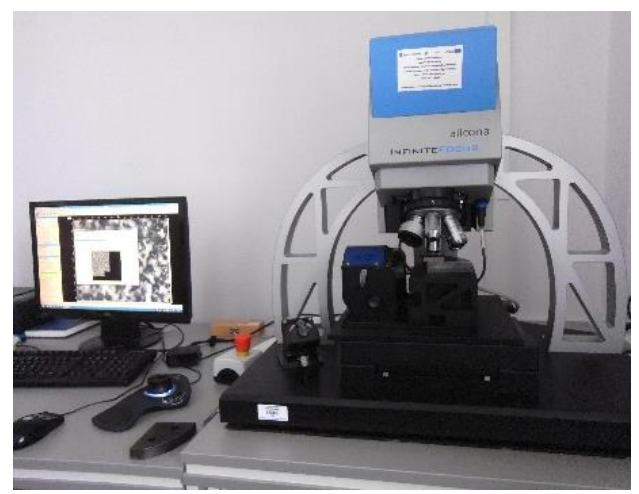

Fig. 2. InfiniteFocus microscope

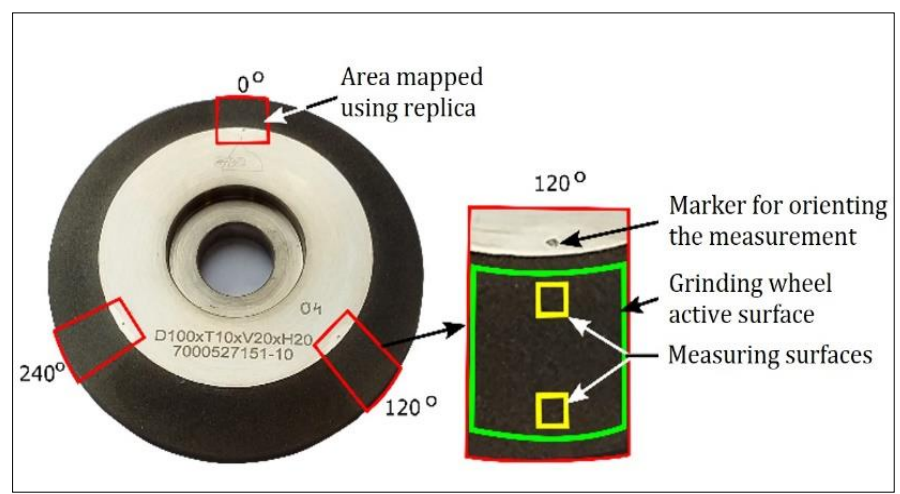

Fig. 3. Location of measuring surfaces on the tested grinding wheel

The GWAS topography was measured five times, i.e. before starting grinding and after achieving the specific material removal volume $V^{\prime}$ equal to $204,476,680$ and $748 \mathrm{~mm}^{3} / \mathrm{mm}$. Six (approximately the same) areas of $2.25 \mathrm{~mm} \times 2.50 \mathrm{~mm}$ were measured at each wear stage. Measuring surfaces were spaced every $120^{\circ}$ around the axis of rotation of the grinding wheel (fig. 3). Two surfaces with different radial positions were measured at each angular position. Vertical resolution of the GWAS topography measurement was $0.1 \mu \mathrm{m}$, and horizontal resolution $-5 \mu \mathrm{m}$. The sampling step was taken as $0.44 \mathrm{~mm} \times 0.44 \mathrm{~mm}$.

MountainsMap Premium 7.4 program [10] was used to pre-process the measurement data, i.e. to remove the shape profile, and to determine the parameters of islands and pores. The shape profile of the measured topographies was filtered by surface fitting described by second-degree polynomials. Individual peaks have also been removed, i.e. unusually high hills and deep pits that often accompany optical measurements.

\section{Extracting areas of abrasive grains and deep pits}

To observe changes in the parameters of islands and pores related to grinding wheel wear, it was necessary that the island and pore cut-off levels used were approximately constant. This condition was to enable comparison of the same grain fragments and the same binder fragments, which are deep recesses, at different stages of wear. In the MountainsMap Premium 7.4 program, the cut-off level is set automatically, but in this case, the results obtained are not satisfactory.

Fig. $4 \mathrm{~b}$ and e show examples of island views above the cut-off level set automatically. As it can be seen, on the used grinding wheel (fig. 4e), the cut-off level is much lower than on the new grinding wheel (fig. 4b). Thus, in the case of the grinding wheel used, not only the fragments corresponding to the abrasive grains were found above the cut-off level, but also areas representing the binder. Therefore, a proprietary algorithm for determining the island and pore cut-off levels was developed. This algorithm is based on determining the average level of binder on GWAS topographies based on the analysis of the material ratio curve. The effects of using the developed method of cutting islands for testing abrasive parameters on GWAS are presented in figs. 4c and f. 


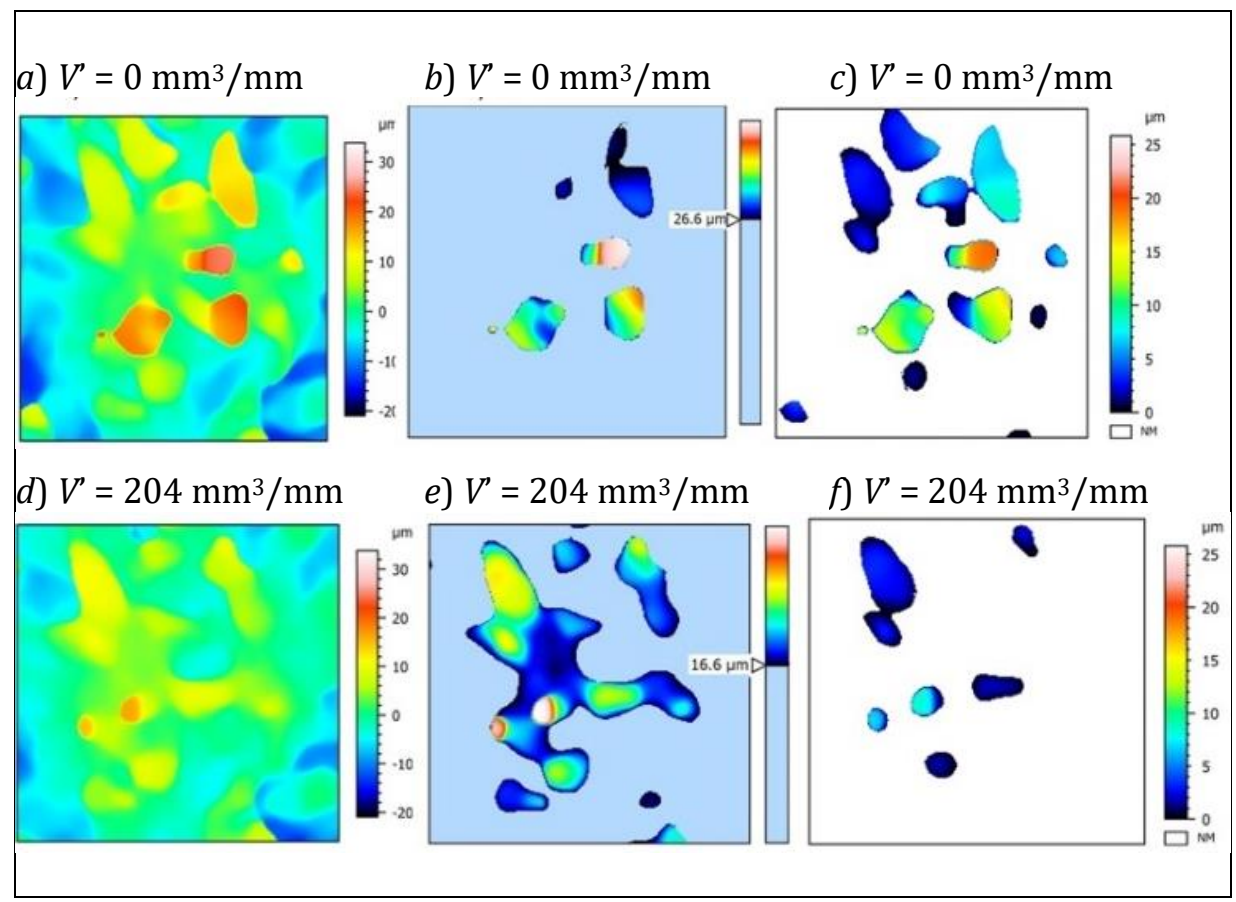

Fig. 4. Fragments of GWAS maps with dimensions of $0.2 \mathrm{~mm} \times 0.2 \mathrm{~mm}$ of the new grinding wheel (a) and after obtaining the specific material removal volume $V^{\prime}=204 \mathrm{~mm}^{3} / \mathrm{mm}$ (d), island views above the cut-off level determined on the basis of the MountainsMap Premium 7.4 program algorithm for $V^{\prime}=0 \mathrm{~mm}^{3} / \mathrm{mm}(b)$ and $V^{\prime}=204 \mathrm{~mm}^{3} / \mathrm{mm} \mathrm{(e)} \mathrm{and}$ based on authors' own algorithm for $V^{\prime}=0 \mathrm{~mm}^{3} / \mathrm{mm}$ (c) and $V^{\prime}=204 \mathrm{~mm}^{3} / \mathrm{mm}(\mathrm{f})$

\section{Recognizing the islands and pores and calculating their parameters}

Islands and pores had to be determined after separating from the measured topography of areas located:

- above the cut-off level of areas associated with abrasive grains,

- below the cut-off level of the deep pit areas. From the point of view of conducted analyses, it was beneficial if one island corresponded to only one grain, and the pores represented individual pits.

In MountainsMap Premium 7.4, two commands are used to determine islands and pores: island analysis and motif analysis.

In the case of island analysis, they are recognized only on the basis of the cut-off level - if the area is above the cut-off level, then it is considered as one island (it is not possible to divide it into two or more islands). In other words: if two grains touched each other above the set cut-off level, they would be recognized as one island (see islands No. 7 and 18 in fig. 5a). The user can only modify vertical coordinate that characterizes the cut-off level. During the tests, the cut-off level for all separated fragments corresponding to grains had to be the same, so that grains were analyzed from the same level at different stages of wear of the grinding wheel. This level was adopted as 0 , i.e. identical to the cut-off plane, which was used to separate the areas filled with grains previously. The same was done for pore recognition.

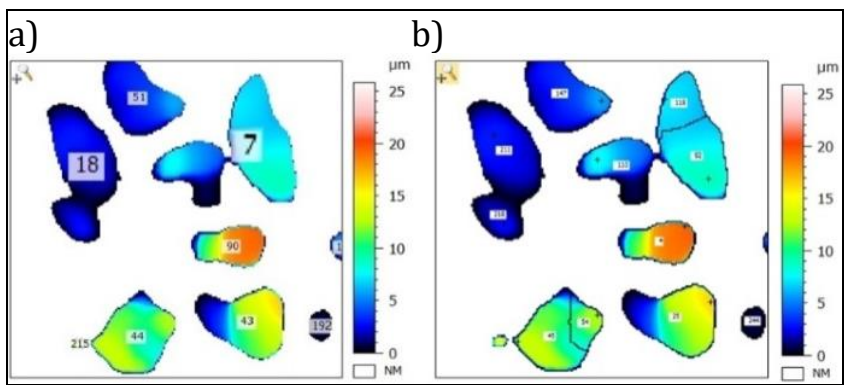

Fig. 5. Islands identified by the command: a) island analysis, b) motif analysis 
Motif analysis, based on watershed segmentation [11], gives more opportunities to separate grains/deep pits, which are connected to each other after initial separation from the measured topography. In this case, the user can change several parameters related to island separation conditions and look for the appropriate island split settings for the best results.

Better separation of islands was obtained using the motif method (fig. 5b), but in this case, the minimum height of motifs did not coincide with the level of islands and pores segmentation and was calculated for each motif individually. For this reason, the altitude parameters of the islands and related volumetric parameters were not determined relative to the base area common for all islands. It can be assumed that the analysis of motifs provided more reliable results regarding the number of islands, while the analysis of islands allowed for a better determination of their total volume. Both methods of determining the islands and pores revealed their advantages and disadvantages, hence it was decided to compare values of island and pore parameters identified by these methods.

\section{Test results}

The main wear processes occurring on the tested GWAS were grains fracture and their removal from the binder $[8,12]$. In the case of pulling the grain out of the binder, a new deep recess was visible on the topography map and in the view showing the pores in the place of the pulled out grain (fig. 6).

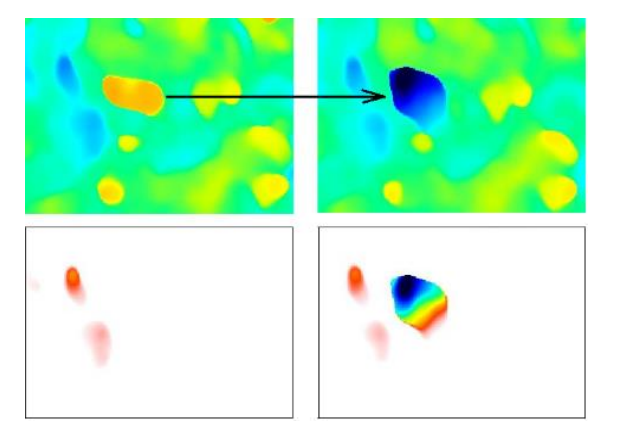

Fig. 6. Example of grain removal. Above, fragments of topography maps for two GWAS states related to different stages of grinding wheel wear, and at the bottom - corresponding views of deep pits

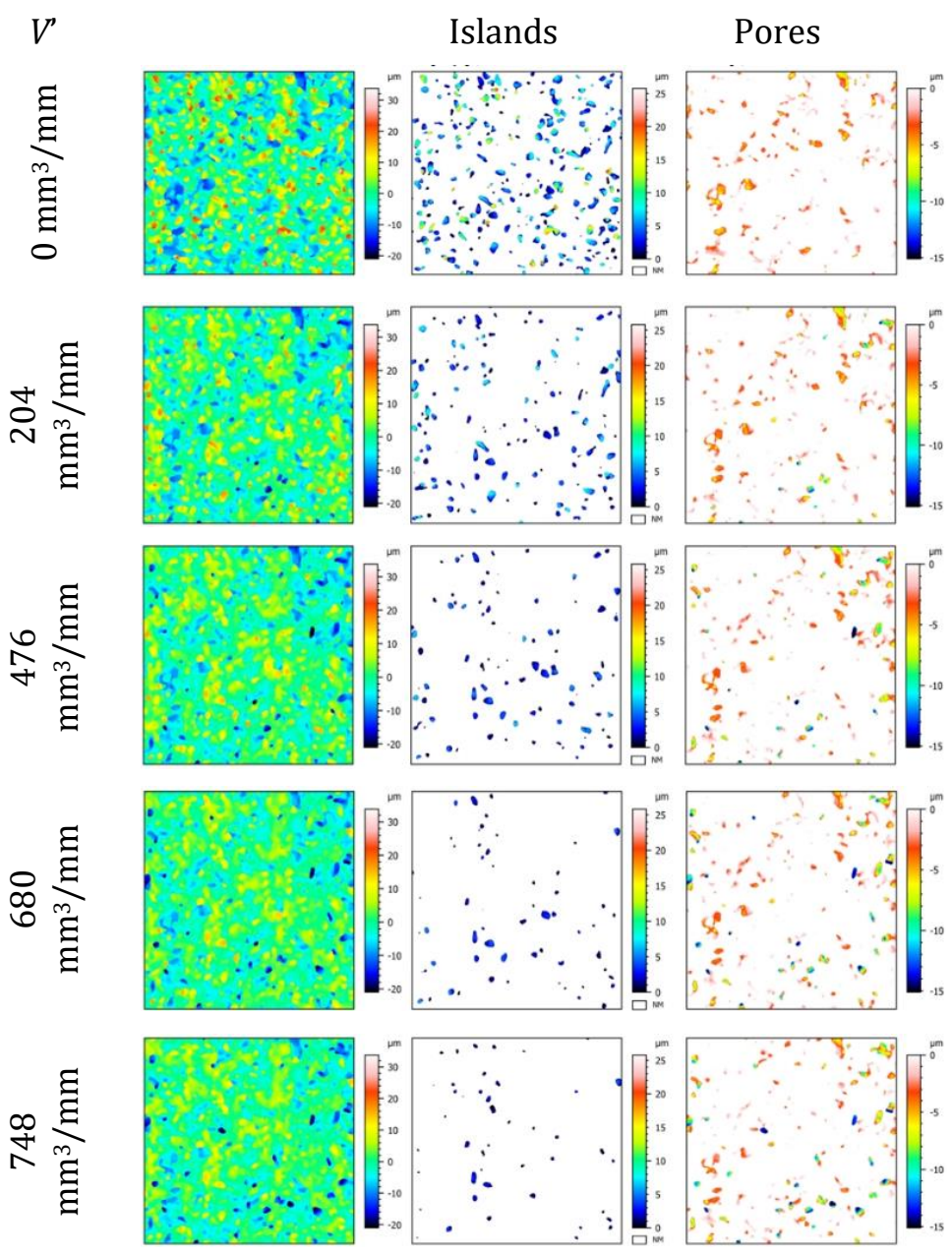

Fig. 7. Topography maps of $1 \mathrm{~mm} \times 1 \mathrm{~mm}$ GWAS fragments at various stages of grinding wheel wear and corresponding views of islands and pores

Fig. 7 shows the same measuring surface fragment $1 \mathrm{~mm} \times 1 \mathrm{~mm}$ after grinding of different volumes of material. The same figure also includes views of the islands and pores separated from the measured topography by means of cut-off levels. It can be seen that at subsequent stages of grinding wheel operation, there was less and less abrasive on its active surface, which resulted in a smaller number of islands and their lower height. 


\section{Comparison of island and pore recognition methods}

Comparison of island and motif analysis methods in the context of island and pore recognition was carried out on the basis of islands, i.e. areas above the set cut-off level, corresponding to abrasive grains.

The graphs in fig. 8 show that in the case of motif analysis, a larger number of $L(w)$ islands was recognized, which resulted in a smaller average surface area of the islands $A(w)$ than in the case of island analysis. The average value of average height of the islands $\operatorname{Zmean}(w)$ and the total volume of islands $V \operatorname{sum}(w)$ were higher in the case of island analysis (fig. 9).

This was due to the fact that in the island analysis, their height parameters were calculated relative to the previously used cut-off level, while in the case of motif analysis, the minimum height of points belonging to the motif did not have to coincide with this cut-off level. The height of the motive could therefore be smaller than if it had been calculated from the cut-off level applied earlier.

The largest differences between effects of the compared methods were visible in the analysis of new grinding wheel topography $\left(V^{\prime}=0 \mathrm{~mm}^{3} / \mathrm{mm}\right)$ and generally decreased with GWAS wear. Larger differences were observed for the altitude Zmean $(w)$ and volumetric parameter Vsum(w) than for the horizontal parameter $A(w)$ and the number of islands $L(w)$.

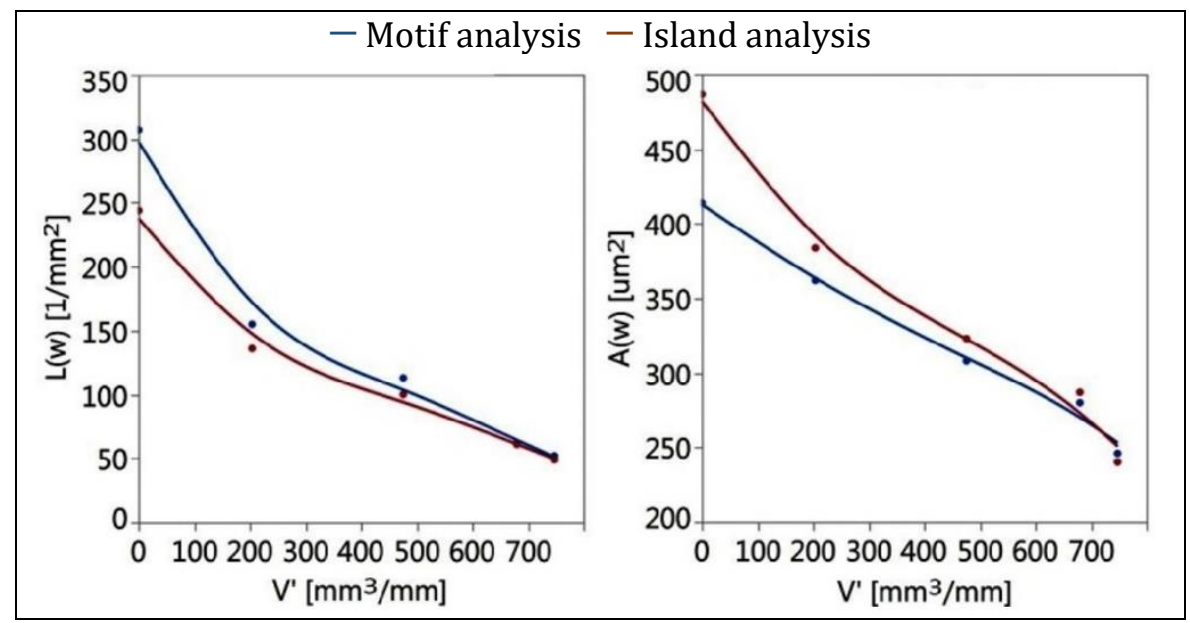

Fig. 8. Comparison of the number of islands $L(w)$ and average surface area of islands $A(w)$ determined by motif analysis and island analysis methods
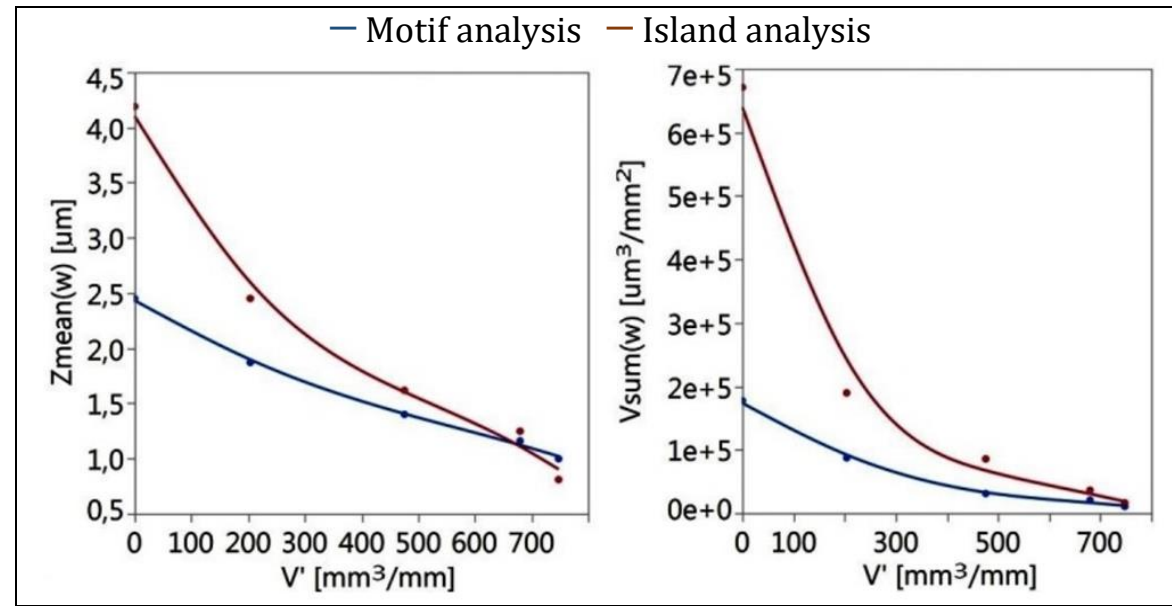

Fig. 9. Comparison of average value of average height of islands Zmean(w) and total volume of islands $\operatorname{Vsum}(w)$, determined by motif analysis and island analysis methods

On the new grinding wheel by motif analysis there were recognized $26 \%$ more grains, and their average surface area was $18 \%$ smaller than in the island analysis method. Relative difference of Zmean $(w)$ parameter was $71 \%$, while $\operatorname{Vsum}(w)$ - as much as $279 \%$.

Considering the comparative studies described, it was found that island and pore recognition is affected by smaller errors when using the island analysis method. It was assumed that the motif analysis provided more reliable results regarding the number of islands, while the analysis of islands allowed for a better determination 
of their total volume. In the case of island analysis, the error in determining their number was smaller than the error of determining the total volume using motif analysis.

Because, according to the manufacturer's data, thickness of the binder layer was $50 \div 60 \%$ of the average grain size, it was assumed that $45 \%$ of the grain volume was above the binder. It was assumed that, a cavity remained in the binder after the pulled out grain, the volume of which was $55 \%$ of the grain volume. On this basis, knowing the difference in pore volume determined for the two states of the grinding wheel, it was possible to determine the volume of abrasive consumed as a result of grain removal [13]. The remaining abrasive loss was attributed to fracture.

Visual analysis of the topography maps and replica surface images showed that cBN grain fracturing was the dominant wear process throughout the entire life of the grinding wheel. Quantitative tests, carried out on the basis of the surface texture parameters of GWAS determined, confirmed that as the volume of removed material increased, the proportion of fracture decreased. After achieving the specific material removal volume $V^{\prime}=204$ $\mathrm{mm}^{3} / \mathrm{mm}$, the proportion of fracture to pull out was $93 \%$ to $7 \%$, while at the end of the test $-71 \%$ to $29 \%$ (fig. 10).

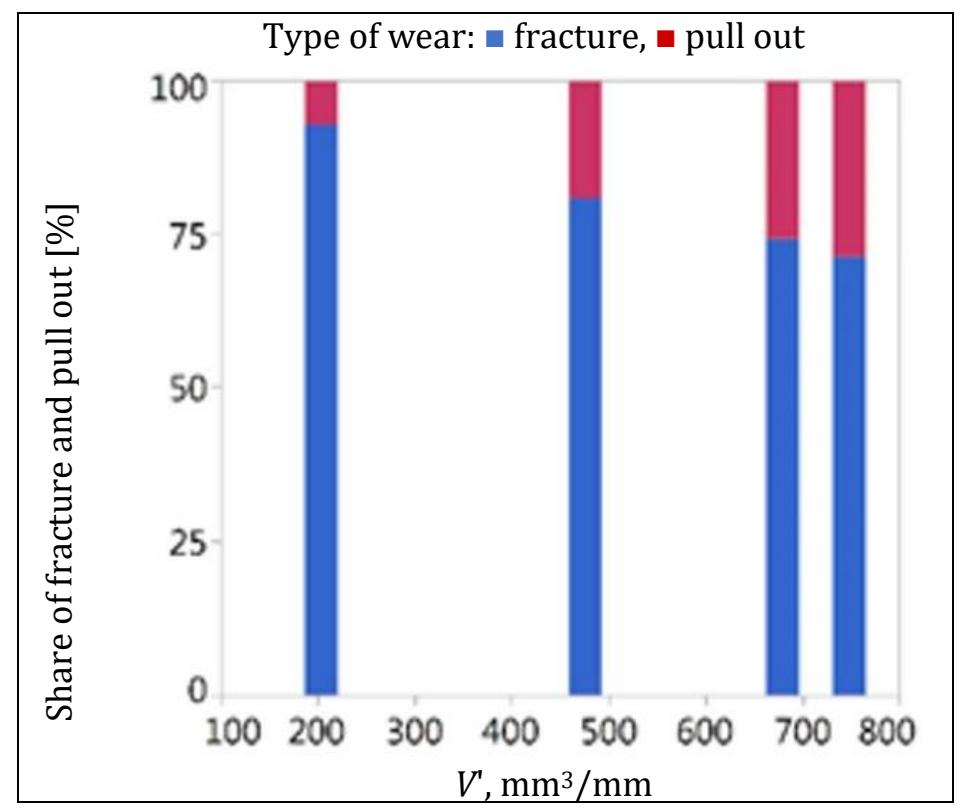

Fig. 10. Volumetric share of various types of grain wear depending on the actual loss of ground material $V^{\prime}$

\section{Summary}

GWAS topography influences the interaction between the grinding wheel and the workpiece during grinding processes. Therefore, this is one of the key factors determining the performance course and effects of the grinding process.

Research aimed at quantifying the topography of the grinding wheel is not easy to perform. It requires the selection of an optimal measuring instrument, allowing for mapping of the grinding wheel microgeometry, and then the appropriate processing of measurement data and calculation of quantitative parameters. It is best if the determined parameters could be easily interpreted and easily associated with various elements of the grinding wheel. An example of such parameters are the parameters of abrasive grains located on GWAS, e.g. grain height or volume.

As part of the research conducted using the MountainsMap Premium 7.4 program, two methods of recognizing the islands and pores on the measured topographies were tested, i.e. island analysis and motif analysis. Regardless of the method used, changes in the analyzed island parameters due to grinding wheel wear were of a similar nature. In the case of the new grinding wheel, i.e. before grinding, significant differences in the numerical values of island parameters identified by both methods were noted. For further testing of GWAS wear, the island analysis method was chosen, which was burdened with a smaller error in determining the volume of the abrasive.

Based on the grinding wheel wear tests, it was determined that cBN grain fracture was the dominant wear process throughout the entire grinding wheel life. With the increase in the volume of removed material, the fracture volume decreased and thus the volumetric share of pulled out grains increased. 


\section{REFERENCES}

[1] Deja M. „Szlifowanie jednostronne z wykorzystaniem ściernic o spoiwie galwanicznym”. Mechanik. 8-9/2015: 84-89, http://dx.doi.org/10.17814/mechanik.2015.8-9.348.

[2] Malkin S., Guo C. "Grinding Technology: The Way Things Can Work: Theory and Applications of Machining with Abrasives". New York: Industrial Press, 2008.

[3] Inasaki I. et al. "4 Grinding, Handbook of Ceramic Grinding \& Polishing". Red. Marinescu D. Norwich, New York: William Andrew Publishing, 1999, 190-323.

[4] Ding W., Xu J., Chen Z., Su H., Fu Y. "Wear behavior and mechanism of singlelayer brazed CBN abrasive wheels during creepfeed grinding cast nickelbased superalloy". The International Journal of Advanced Manufacturing Technology. 51 (2010): 541-550.

[5] Salmon S. C. "Grinding is high-tech". Manufacturing Engineering. 143 (2009): 53-59.

[6] Zhi G. et al. "The measurement and analysis of micro bonding force for electroplated CBN grinding wheels based on response surface methodology". Engineering Failure Analysis. 57 (2015): 377-388.

[7] Bazan A., Kawalec A. „Metody opisu topografii powierzchni ściernic”. Mechanik. 89 (2013): 28-37.

[8] Kacalak W., Tandecka K., Lipiński D., Szafraniec F., Socha E. „Metody identyfikacji zmian stanu czynnej powierzchni ściernic w wyniku starcia, zalepiania lub wykruszania ziaren”. Mechanik. 8-9 (2014): 193199.

[9] Kawalec A., Bazan A., Krok M. „Wpływ prędkości szlifowania na zużywanie się ściernicy z nasypem z cBN, ze spoiwem nanoszonym galwanicznie". Mechanik. 8-9 (2017): 690-692, https://doi.org/10.17814/mechanik.2017.8-9.101.

[10] www.digitalsurf.com (access: 18.05.2018).

[11] Wojnar L., Majorek M. „Komputerowa analiza obrazu”. Kraków: FotobitDesign, 1994.

[12] Shi Z., Malkin S. "An investigation of grinding with electroplated CBN wheels". CIRP Annals - Manufacturing Technology. 52 (2003): 267-270.

[13] Kawalec A., Bazan A. „Ilościowy opis form zużycia jednowarstwowych ściernic z cBN, pracujących z różnymi prędkościami". Mechanik. 10 (2018): 803-805, https://doi.org/10.17814/mechanik.2018.10.134. 